\title{
Study on glaucoma awareness among the rural population of central Kerala
}

\author{
Nirmala ${ }^{1}$, Antharjanam $D^{2}$, Krishnan $G^{3}$, Harsha C.H. ${ }^{4}$, Mary $A_{n n}{ }^{5}$, Londhe $S^{6}$, Antony $R^{7}$ \\ ${ }^{1}$ Dr. Nirmala, Department of Ophthalmology, ${ }^{2}$ Dr Devaki Antharjanam, Assistant Professor, Department of Community \\ Medicine, ${ }^{3}$ Dr Gopalakrishnan P, Associate Professor, Department of Community Medicine, ${ }^{4}$ Ms Harsha C.H, Assistant \\ Professor, Bio-Statistics, Department of Community Medicine, ${ }^{5}$ Dr. Ann Mary, Assistant Professor, Department of \\ Community Medicine, ${ }^{6}$ Dr. Swathy Londhe, Professor, Department of Community Medicine, ${ }^{7}$ Dr Raju Antony, Professor \\ $\&$ HOD, Department of Community Medicine; all authors are attached with SNIMS, Chalakka, Ernakulam.
}

Address for Correspondence: Dr. Nirmala, Department of Ophthalmology, Sree Narayana Institute of Medical Sciences, Chalakka, Ernakulam. E-Mail ID: nimma.prabhu@gmail.com

\begin{abstract}
Background: Glaucoma is one among the leading causes of irreversible blindness in India. Lack of awareness and lack of knowledge of this disease is the most important cause for the late presentation which leads to blindness. Aim: To find out the awareness and knowledge about glaucoma in a rural population of a literate state like Kerala. Study Design: A cross sectional study using a pre tested semi structured questionnaire and the participants were selected by cluster sampling method. Materials and Methods: The questionnaire contained details of demographic factors in the first part and questions to assess the knowledge of the participants who were aware of this disease in the second part. The responses were entered in MS EXCEL Sheet and data analysis done using the software SPSS version 15.Chi-square test was done to find out the percentage and proportion. Results: Out of the 4414 participants 2052 were males and 2362 were females. $805(18.23 \%)$ people were aware of glaucoma, Awareness was statistically significant in terms of age, age group 40-59 were more aware of the disease. Knowledge of glaucoma was significant statistically in terms of education ( $\mathrm{p}$ value $=0.003$ ) but not in terms of gender ( $\mathrm{p}$ value -0.847 ) Major source of information was through mass media. Only $34.4 \%$ knew that this is a disease with no symptoms. Conclusion: Awareness of glaucoma is less when compared to the literacy rate. But knowledge of glaucoma is good among those who are aware of the disease. Mass Media can be utilized to impart knowledge of this disease. Health education classes should be conducted and people should be motivated to undergo screening procedures so that early detection is possible.
\end{abstract}

Keywords: Glaucoma awareness, Knowledge, Primary Open Angle Glaucoma (POAG), Rural population.

\section{Introduction}

Glaucoma is one among the leading causes of blindness around the world. Dandona et al estimated the number of blind people in India to be 18.7 million in 2000 and if the current trend continues it may increase up to 31.6 by 2020. To avoid this, effective methods have to be adopted to detect and treat various diseases like cataract, refractive error, glaucoma etc [1]. A study conducted by Quigley et al reported that the number of glaucoma patients will increase from 60.5 to 79.6 million world over and Glaucoma will be the second

Manuscript received $14^{\text {th }}$ August 2016

Reviewed: $26^{\text {th }}$ August 2016

Author Corrected: $7^{\text {th }}$ September 2016

Accepted for Publication $22^{\text {nd }}$ September 2016 leading cause of blindness worldwide [2]. George et al reported that in India around 11.2 million people aged above 40 are affected with glaucoma. Out of this 6.48 million were diagnosed to have Primary Open Angle Glaucoma (POAG) [3].

Studies showed that prevalence of this disease increases with age and $>90 \%$ are unaware of this disease. [4] In a study done at Andhra Pradesh the prevalence rate of POAG $>30$ years was $1.62 \%$ in urban population. Other studies reported the prevalence of glaucoma in India to be $2.6 \%-4.1 \%$ [5]. A research done among the Indians, Malay and Chinese population in Singapore showed 
that the prevalence of this disease was less in Indians when compared to others [6].

Glaucoma is described as a silent killer of sight as it is a disease with few or no symptoms. The progression is very insidious that the patient becomes aware of the disease in the late stage only. This may be one of the reasons for low prevalence. Lack of awareness on glaucoma among the rural population of South India was reported by Krishnaiah et al. [7].

As this leads to blindness, an efficient way to educate the population is necessary to detect the disease at an early stage and thus help to decrease the ill effects of the disease [8] The study by Gogate et al found that late presentation of glaucoma can be attributed to the lack of awareness and education [9].

Another study concentrating the Northern part of India keep proving the fact that education and awareness can prevent glaucoma related blindness [10].

The trouble of glaucoma is huge and undetected according to available evidence and is expected to rise further with the ageing population. Training skills are essential to diagnose and treat glaucoma before visual morbidity sets in and a significant impact on quality of life occurs. Otherwise millions will continue to suffer with this blinding disease [11].

According to the survey conducted by NPCB in 20012002, number of blind people in Kerala due to glaucoma was 54867 (5.8\% of total blind population > 50) [12].

Kerala census population data 2011 reported the literacy rate of Kerala to be $94 \%$ which is equivalent to that of a developed nation. The aim of this study is to find out the awareness of glaucoma among the rural population of Kerala. This will help us to find out an effective way to tackle blindness due to glaucoma.

\section{Materials and Methods}

The study design was approved by the Ethics Committee of the Institution. A cross sectional study using a pre tested semi structured questionnaire was conducted in the rural area of Parakkadavu Block Panchayath, participants were selected by cluster sampling method. Questionnaire contained two parts. In the first part question regarding the socio demographic factors like name, age, education and occupation were included. A question regarding the awareness of glaucoma was also included. The second part contained multiple choice questions to test the knowledge of the subject about glaucoma. Each question contained three responses (1. Yes, 2. No, 3. Don't know). The subject was asked to tick the right response for each question. Question regarding the source of knowledge was also included in the questionnaire. Initially a pilot study was conducted using the same questionnaire on 100 people to estimate the sample size. Fifteen percent were aware of the disease. The approximate population of the block was 139853 in 2011 census, the required sample size was 4288. 165 anganwadi teachers in the Parrakkadavu Block Panchayath were selected to distribute questionnaire. Only the first part of the questionnaire was given to each family and they were asked to fill up the the demographic details and whether how many of them have heard of glaucoma. They were asked to return the questionnaire on the next day itself. After writing the name of those who have heard of glaucoma on the second questionnaire it was sent to the subject to fill it up and return it on the next day itself. 4500 people were selected but 4414 subjects above 20 years of age who gave consent to participate in the study were included in the study. Data collected was entered in MS EXCEL and statistical analysis was conducted using the software SPSS version 15. Mean, Standard deviation, Frequency and Percentage were calculated, Chi square test was done to find the relationship between awareness and demographic factors. $\mathrm{p}<.05$ was considered as statistically significant.

\section{Results}

A total of 4414 people aged 20 and above, responded. Out of the total participants $2052(46.5 \%)$ were males and 2362 $(53.5 \%)$ females.

The mean age and SD was 44 (16) (range 20-93) years. 805 (18.23\%) people of the total participants were aware of the disease- glaucoma, 402 Males (19.6\%) and 403 females (17.0\%).

Out of 4414 subjects only $16(0.36 \%)$ were illiterate and none of them had heard of glaucoma. Those who have heard of glaucoma majority were having good knowledge $(63.4 \%)$ and rest $(36.6 \%)$ had satisfactory knowledge. 
Table- 1: Comparison between age of respondents and their awareness of Glaucoma.

\begin{tabular}{|c|c|c|c|c|}
\hline Age (years) & Aware & Not aware & Total & p- value \\
\cline { 1 - 4 } $20-39$ & $350(16.8 \%)$ & $1735(83.2 \%)$ & $2085(100 \%)$ & 0.018 \\
\cline { 1 - 3 } & $296(20.5 \%)$ & $1147(79.5 \%)$ & $1443(100 \%)$ & $886(100 \%)$ \\
\hline$>60$ & $159(17.9 \%)$ & $727(82.1 \%)$ & $\mathbf{4 4 1 4}$ & \\
\hline
\end{tabular}

In age group 20-39years 350 (16.8\%), in age group 40-59years $296(20.5 \%)$ and >60 years $159(17.9 \%)$ were aware of glaucoma. This difference was statistically significant $(\mathrm{p}=0.018)$

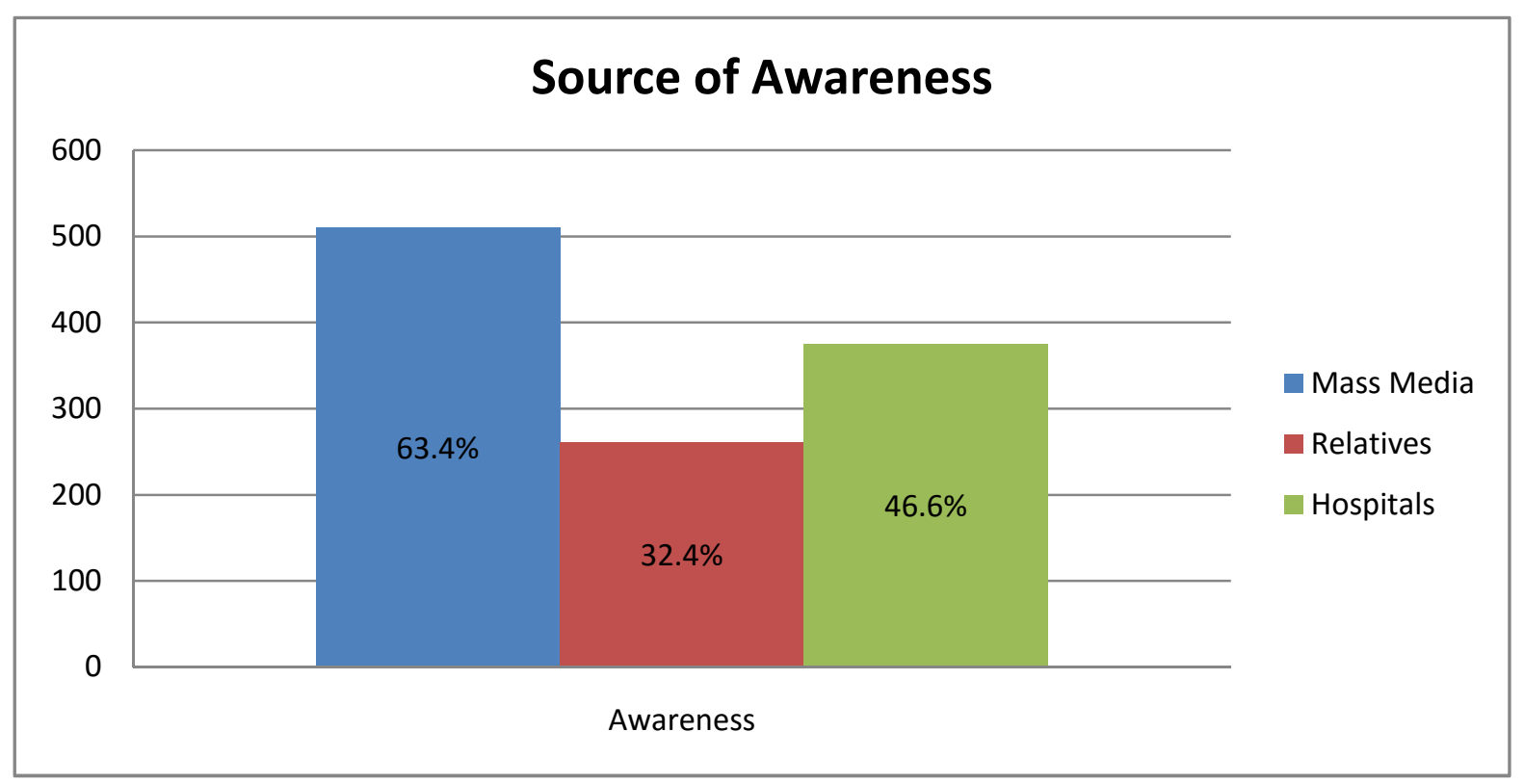

Figure- 1

Majority (63.4\%) gained knowledge through mass media.

Table-2: Responses to the questions by 805 participants

\begin{tabular}{|c|l|c|c|c|}
\hline $\begin{array}{c}\text { Sl } \\
\text { No }\end{array}$ & \multicolumn{1}{|c|}{ Question } & Right Answer & Wrong Answer & Don't Know \\
\hline 1 & $\begin{array}{l}\text { High intraocular pressure damages } \\
\text { the nerves causing blindness. }\end{array}$ & $689(85.6 \%)$ & $35(4.3 \%)$ & $81(10.1)$ \\
\hline 2 & $\begin{array}{l}\text { Peripheral visual field is affected in } \\
\text { this disease. }\end{array}$ & $670(83.2 \%)$ & $34(4.2 \%)$ & $101(12.5 \%)$ \\
\hline 3 & No Symptoms/ few symptoms. & $277(34.4 \%)$ & $210(26.1 \%)$ & $380(39.6 \%)$ \\
\hline 4 & $\begin{array}{l}\text { Eye drops are available for the } \\
\text { disease. }\end{array}$ & $400(49.7 \%)$ & $121(15 \%)$ & $284(35.3 \%)$ \\
\hline 5 & Heredity has a role in this. & $275(34.2 \%)$ & $270(33.5 \%)$ & $260(32.3 \%)$ \\
\hline 6 & Disease can be prevented. & $392(48.7 \%)$ & $139(17.3 \%)$ & $274(34.0 \%)$ \\
\hline 7 & Disease is caused by cataract. & $412(51.2 \%)$ & $130(16.1 \%)$ & $263(32.7 \%)$ \\
\hline
\end{tabular}

Majority $(85.6 \%)$ of the participants knew the disease causes damage to the nerves resulting in blindness. Very few $(34.4 \%)$ were aware that this is a disease with few or no symptoms and heredity has a role in it. 
Table-3: Relation between Education and Knowledge of glaucoma.

\begin{tabular}{|c|c|c|c|c|}
\hline Education & $\begin{array}{l}\text { Satisfactory } \\
\text { Knowledge }\end{array}$ & Good Knowledge & Total & p Value \\
\hline Up to $10^{\text {th }} \mathrm{Std}$ & $82(46.9 \%)$ & $93(53 \%)$ & $175(100 \%)$ & \multirow{4}{*}{0.003} \\
\hline+2 and diploma & $150(35.5 \%)$ & $272(64.5 \%)$ & $422(100 \%)$ & \\
\hline $\begin{array}{l}\text { Graduate and post } \\
\text { graduate }\end{array}$ & $63(30.3 \%)$ & $145(69.7 \%)$ & $208(100 \%)$ & \\
\hline Total & 295 & 510 & 805 & \\
\hline
\end{tabular}

As level of education increases knowledge also increases and it is statistically significant ( $\mathrm{p}$ value $=0.003$ )

Table-4: Relation between Gender and Knowledge.

\begin{tabular}{|c|c|c|c|c|}
\hline Gender & $\begin{array}{c}\text { Satisfactory } \\
\text { Knowledge }\end{array}$ & Good Knowledge & Total & \multirow{2}{*}{ p Value } \\
\hline Male & $149(37 \%)$ & $254(63 \%)$ & $403(100 \%)$ & \multirow{2}{*}{0.847} \\
\hline Female & $146(36.3 \%)$ & $256(63.7 \%)$ & $402(100 \%)$ & 805 \\
\hline Total & 295 & 510 & \\
\hline
\end{tabular}

Level of knowledge is equal for both genders . p value 0.847 is not significant

\section{Discussion}

POAG is considered as one among the leading causes for irreversible blindness. The progression can be prevented by early detection of the diseases. Lack of awareness about the diseases is the major barrier to its detection. The present study conducted in the rural population of a highly literate state like Kerala reported that only $18.24 \%$ is aware of the disease. The studies conducted at USA (72\%), Singapore (23\%), Germany (75\%) [13'14'15] revealed a higher rate of awareness. However, similar studies conducted among the rural populations of India reported a very low rate of awareness.

Education and age play a very important role in the awareness of the disease. $63.4 \%$ of the subjects who were aware of the disease had a good knowledge regarding the disease and the major source of information was mass media. 40-59 age group were more aware than other age groups. People at the age of 40 should undergo screening tests so that disease can be detected at an early stage. As level of education increases awareness and knowledge increases [10]. In our study graduates and post graduates had good knowledge $(69.7 \%)$ There is not much difference in relation with awareness among males and females. Studies conducted in the urban population of Chennai stated that younger age, men and low level of education are the three factors for lack of awareness [8]. Majority $(85.6 \%)$ of the subjects were aware of the fact that in glaucoma the raised intraocular pressure damages the nerve resulting in blindness. But very few (34.4\%) knew that this is a disease with few or no symptoms. This may be one of the reasons people are not approaching an ophthalmologist for screening. More health awareness programs has to be conducted and importance should be given to highlight the fact that glaucoma is a disease with no symptoms. Proper health education is very important for the early detection of the disease. Studies done in Uk reported that effective source of information of the disease is through mass media [16]. In our study we too found out that the majority gained information through mass media. But other studies conducted in various parts of India reported that the major source of information was from relatives and health professionals. This shows the importance of conducting more glaucoma awareness classes in rural as well as urban areas.

\section{Conclusion}

Even though the literacy rate of Kerala is comparable to that of a developed country the awareness is significantly less. This study highlighted the fact that providing health education is the first step in the prevention of the disease. Importance should be given to the fact that glaucoma is a disease with few or no symptoms and early detection can help in preventing blindness. We can utilize the mass media to educate the people. But at the same time frequent health awareness classes should be arranged so that knowledge level of 
the people improves and they will be willing to undergo screening of this disease. This in turn will help in preventing blindness due to glaucoma.

Acknowledgement- Authors are grateful to the patients who participated in this study, Anganwadi workers who helped us to conduct this study, Child Development Project Officer Parakkadavu Block Panchayath who gave consent to this study, HOD and staff of Community Medicine Department for their support in this study.

Funding: Nil, Conflict of interest: None initiated, Permission from IRB: Yes

\section{References}

1. Dandona L, Dandona R, John RK. Estimation of blindness in India from 2000 through 2020: implications for the blindness control policy. Natl Med J India. 2001 Nov-Dec;14(6):327-34.

2. Quigley HA, Broman AT. The number of people with glaucoma worldwide in 2010 and 2020. Br J Ophthalmol. 2006 Mar; 90(3):262-7.

3. George R, Ve RS, Vijaya L. Glaucoma in India: estimated burden of disease. J Glaucoma. 2010 Aug;19 (6):391-7. doi: 10.1097/IJG.0b013e3181c4ac5b.

4. Vijaya L, George R, Baskaran M, Arvind H, Raju P, Ramesh SV, et al. Prevalence of primary open-angle glaucoma in an urban South Indian population and comparison with a rural population. The Chennai glaucoma study. Ophthalmology. 2008;115:648-54.

5. Jacob A, Thomas R, Koshi SP, Braganza A, Muliyil J. Prevalence of primary glaucoma in an urban south Indian population. Indian J Ophthalmol. 1998 Jun;46 (2):81-6.

6. Narayanaswamy A, Baskaran M, Zheng Y, Lavanya R, Wu R, Wong WL, Saw SM, Cheng CY, Wong TY Aung $\mathrm{T}$, The Prevalence and types of glaucoma in an urban population: The Singapore Indian Eye Study, Invest Ophthalmol Vis Sci.2013Jul 10;54 (7):4621-7.
7. Krishnaiah S, Kovai V, Srinivas M, Shamanna BR, Rao GN, Thomas R. Awareness of glaucoma in the rural population of Southern India. Indian $\mathbf{J}$ Ophthalmol. 2005 Sep;53(3):205-8.

8. Tenkir A, Solomon B, Deribew A. Glaucoma awareness among people attending ophthalmic outreach services in Southwestern Ethiopia. BMC Ophthalmol. 2010;10:17.

9. Gogate P, Deshpande R, Chelerkar V, Deshpande S, Deshpande $\mathrm{M}$. Is glaucoma blindness a disease of deprivation and ignorance? A case-control study for late presentation of glaucoma in India. Indian J Ophthalmol. 2011 Jan-Feb;59(1):29-35.

10. Rewri P, Kakkar M. Awareness, knowledge, and practice: a survey of glaucoma in north Indian rural residents. Indian J Ophthalmol. 2014 Apr;62(4):482-6. doi: 10.4103/0301-4738.132105.

11. Manish Pandey MS, Ronnie George,L Vijaya, Epidemiology of glaucoma in South India, KSOS. March 2014; Vol,xxvi,No.1

12. Glaucoma- Leading Cause of Blindness NPCB npcb. nic.in/mainlink file/File 302.pdf

13. Gasch AT, Wang P, Pasquale LR. Determinants of glaucoma awareness in a general eye clinic. Ophthalmology. 2000 Feb;107(2):303-8.

14. Saw SM, Gazzard G, Friedman D, Foster PJ, Devereux JG, Wong ML, Seah S. Awareness of glaucoma, and health beliefs of patients suffering primary acute angle closure. Br J Ophthalmol. 2003 Apr;87(4):446-9.

15. Pfeiffer N, Krieglstein GK, Wellek S. Knowledge about glaucoma in the unselected population: A German survey. J Glaucoma. 2002;11:458-63.

16. Baker H, Murdoch IE. Can a public health intervention improve awareness and health-seeking behaviour for glaucoma? Br J Ophthalmol. 2008 Dec; 92(12):1671-5. doi: 10.1136/bjo.2008.143537. Epub 2008 Oct 6.

\section{How to cite this article?}

Nirmala, Antharjanam D, Krishnan G, Harsha C.H, Mary Ann, Londhe S, Antony R. Study on glaucoma awareness among the rural population of central Kerala.Int J Med Res Rev 2016;4(9):1582-1586.doi:10.17511/ijmrr. 2016.i09.11. 